'Laboratorio Integrativo de Biomecánica y Fisiología del Esfuerzo (LIBFE), Escuela de Kinesiología, Facultad de Medicina, Universidad de los Andes. Santiago, Chile.

El autor declara no tener conflictos de interés. Trabajo no recibió financiamiento.

Recibido el 11 de abril de 2018 , aceptado el 13 de septiembre de 2018.

Correspondencia a:

Dr. Oscar F. Araneda Valenzuela Monseñor Álvaro del Portillo 12.455,

Las Condes, Santiago, Chile. ofaraneda@miuandes.cl

\section{Oscar Castro Zúñiga: el poeta vencido por la tuberculosis}

\author{
OSCAR F. ARANEDA VALENZUELA ${ }^{1}$
}

\section{Oscar Castro Zúñiga, the poet who succumbed to tuberculosis}

The life of the renowned Chilean writer, Oscar Castro Zúñiga, was interrupted early, when he was 37 years old. He acquired tuberculosis during the epidemic in our country between the second half of the nineteenth century and the first half of the twentieth century. He developed the disease during a crucial stage in terms of diagnosis and treatment, coinciding with the end of the sanatorium stage and the first chemotherapeutic attempts. The symptoms and treatments of the disease in that age are described analyzing the letters, both written by himself and by people close to him and the biographies published during the historical and personal context of the artist.

(Rev Med Chile 2018; 146: 1190-1196)

Key words: Chile; History of Medicine; Streptomycin; Tuberculosis.

\section{Breve biografía}

scar Castro Zúñiga (1910-1947) fue un escritor autodidacta nacido en Rancagua. Tuvo una vida con problemas económicos e inestabilidad laboral, desempeñándose como empleado de banco, dependiente de un molino, administrador de una librería, periodista, bibliotecario y docente ${ }^{1}$. Su vida transcurrió principalmente en su ciudad natal, que, en ese período, poseía casi $30 \%$ de analfabetismo, falta de atención médica y una población que se triplicó entre 1907 y $1940^{2,3}$, al comenzar la explotación del yacimiento minero "El Teniente".

A pesar de este escenario personal y social, participó en la fundación del grupo literario "Los Inútiles" , donde formó fuertes vínculos con los escritores Gonzalo Drago (1906-1994), Raúl González Labbé (1908-1998), quienes, junto a su esposa Isolda Pradel (1915-2012), se convertirían en testigos directos de su enfermedad y posteriormente sus biógrafos. Castro obtuvo un lugar en la literatura de su siglo por su autenticidad, técnica literaria y lenguaje. Su temática abarca temas históricos, amorosos, la infancia, la margi- nalidad urbana, la vida rural y las faenas mineras que plasmó en sus poemarios; Camino en el alba (1937), Las alas del fénix (1943), Viaje del alba a la noche (1938), Reconquista del hombre (1944), Glosario gongorino (1948), Rocío en el trébol (1950) $\mathrm{y}$ en sus cuentos y novelas; Huellas en la tierra (1940), Comarca del jazmín (1945), Llampo de sangre (1950), La vida simplemente (1951), Lina y su sombra (1965) y El valle de la montaña (1967).

\section{Su enfermedad}

En sus antecedentes médicos se menciona "tos convulsiva" y "peste cristal" en la infancia ${ }^{5}$. En la adultez destaca el ser fumador moderado y presentar un bajo consumo de alcohol, al respecto, Gonzalo Drago dice:

"Bebía muy poco. Su salud, su hígado delicado no le permitían excesos alcohólicos. Fumaba moderadamente"

A pesar de esta referencia de "problemas hepáticos", no existen antecedentes que lo con- 
firmen, tampoco antecedentes de poseer alguna enfermedad crónica, lo que es esperable en vista de su muerte a temprana edad. Respecto al cuadro de tuberculosis, el primer antecedente es aportado por González Labbé:

"1944.-[...] Comienza a padecer los primeros sintomas de la enfermedad que lo abatirá"7.

A pesar de lo anterior, no existen en sus cartas ni en otros documentos personales, ninguna referencia a que sus molestias comenzaran el año 1944. Una información más consistente sitúa el inicio de su cuadro en el año 1945, como es relatado por su esposa:

“...empezaron los resfríos y aumentaron las trasnochadas. Los doctores amigos, le recomendaron prudencia con los resfríos continuados y las trasnochadas, porque los resultados podrían ser muy caros..."

Por la misma época, en carta enviada por González Labbé a Drago, fechada el 18 de mayo de 1945, dice:

"Apreciado amigo: Como el cuervo negro de Poe llego de nuevo a golpear tu ventana con malas nuevas: Oscar, nuestro amigo querido, está francamente enfermo. El mal de los poetas y escritores de nuestra tierra chilena, lo ha marcado también a él... "6.

Esta carta corresponde al primer antecedente explícito del inicio de la enfermedad. En vista de su fecha, es probable que efectivamente sus síntomas iniciaran meses antes de su diagnóstico, como mencionaba previamente el mismo autor de esta carta $^{7}$. En la misma línea, el 4 de junio de 1945, el poeta le informa a Drago de su situación médica:

"Había postergado deliberadamente hasta hoy la respuesta a tu carta última, en espera de que los médicos me leyeran la sentencia. Ahora ya lo conozco. Es algo simple y tremendo: tres meses de cama, sobrealimentación, reposo. Ni siquiera me permiten levantarme en días de sol tan radiante como éste. Y lo peor es que, según parece, la receta me será repetida cuando se cumplan estos noventa días".

Su esposa relata que fue atendido en el "Servicio Nacional de Salud”, lo que probablemente corresponde al Servicio de Medicina Preventiva de la Caja de Empleados Públicos, en vista de su trabajo como bibliotecario en el Liceo de Hombres de Rancagua. Este momento del diagnóstico fue narrado por ella así:

"Fue a Santiago al Servicio Nacional de Salud, después de varios exámenes los médicos diagnosticaron: broncoestasia y por esa enfermedad fue atendido casi un año por los mismos médicos.

En 1945, los doctores le recetaron clima y seis meses de reposo. Se fue a Machali"'.

El diagnóstico de bronquiectasia aparece también señalado por otros biógrafos en los momentos finales de su enfermedad, interpretándole como una entidad clínica fuera del contexto de la tuberculosis, sin embargo, lo más probable es que este cuadro derive de su enfermedad de base. Más aún, González Labbé, en mayo de 1945, en la carta descrita previamente ${ }^{6}$, afirma que el poeta sufre de tuberculosis, denominándola como "el mal de los poetas", su testimonio es de particular relevancia en vista de su condición de odontólogo.

En otro aspecto, destaca la indicación médica de reposo y la posibilidad de ausentarse de su trabajo, lo que se explica en la aplicación de la Ley de Medicina Preventiva de $1938^{10}$ de reciente implantación. El envío a su casa se explica por la ausencia de un sanatorio en Rancagua y sus alrededores ${ }^{11}$. Por esta razón, el poeta acude a la localidad precordillerana de Machalí, donde permaneció en una pensión, buscando los beneficios de la altura.

En carta fechada el 10 de junio de 1945, enviada al poeta por el crítico literario Hernán Díaz Arrieta (1891-1984), encontramos una nueva referencia a su recién diagnosticada enfermedad:

"Mi querido amigo, no sabe la impresión o, mejor, las impresiones que su carta me ha producido [.....] Primero, naturalmente, la sorpresa y el pesar profundísimo de saberlo enfermo. ¡Espero que no sea grave!"12.

Más adelante, en la misma, le aconseja recurrir a la atención prestada por el sistema de Medicina Preventiva:

"La ley de la Preventiva me parece una bendición. Ya supe, hace poco, de una vida salvada, así, literalmente, salvada gracias al examen oportuno $y$ al reposo posible mediante el sueldo integro por 
plazo indefinido [..... ¿Qué hubiera sido sin la ley Cruz-Coke? Mejor no pensarlo" ${ }^{12}$.

En otra misiva de este mismo autor, fechada el 11 de julio de 1945, le dice:

“...Su deseo de salir a andar por una calle tranquila, esa desesperación de estar inmóvil jcómo lo comprendo! [.... ] Hasta luego. Descanse, cuídese y tenga la certeza de que mejorará.... "13.

El 17 de junio de 1945, Castro fue declarado hijo ilustre de Rancagua. Su estado fue descrito de la siguiente manera:

"Para asistir al homenaje público que se le rendía, hubo de suspender su reposo y abandonar el lecho en que permanecía confinado por prescripción médica. Intensamente pálido, emocionado, el poeta agradeció el clamoroso aplauso".

En esta descripción aparece por primera vez mencionada la palidez. Además, es posible apreciar su aspecto de enfermo en una fotografia de ese año 1945 (Figura 1), cerca de la fecha en la que se le homenajeó.
Avanzado el reposo, otra carta enviada a Drago, el 28 de julio, hace aportes respecto a la situación de aquellos días:

"Estuve con un ataque de asma cuyos accesos se me prolongaron por más de dos semanas, produciéndome un terror que me impedia pensar en otra cosa que no fuese el próximo ahogamiento. [...] En cuanto a lo otro, al pulmón, parece que la cosa marcha de modo excelente. No me extrañaría en absoluto que me reincorporaran a mis labores en el mes de septiembre...".

Esta carta tiene la importancia de señalar la presencia de un cuadro catalogado como "asma". Previamente, la referencia a esta patología se encuentra en una de las cartas de un viaje a las termas del Flaco en el verano de $1945^{14}$, donde refiere que luego de ingerir un fármaco que no identifica, "Me ha bastado para curarme. Creo que ya no tendré ningún miedo al asma". Aparte de estas dos referencias, no hay antecedentes de la presencia de este cuadro en otros momentos de su vida, lo que dificulta afirmar que se trate de esta patología, más bien, es probable que el cuadro descrito corresponda a hiperreactividad bronquial

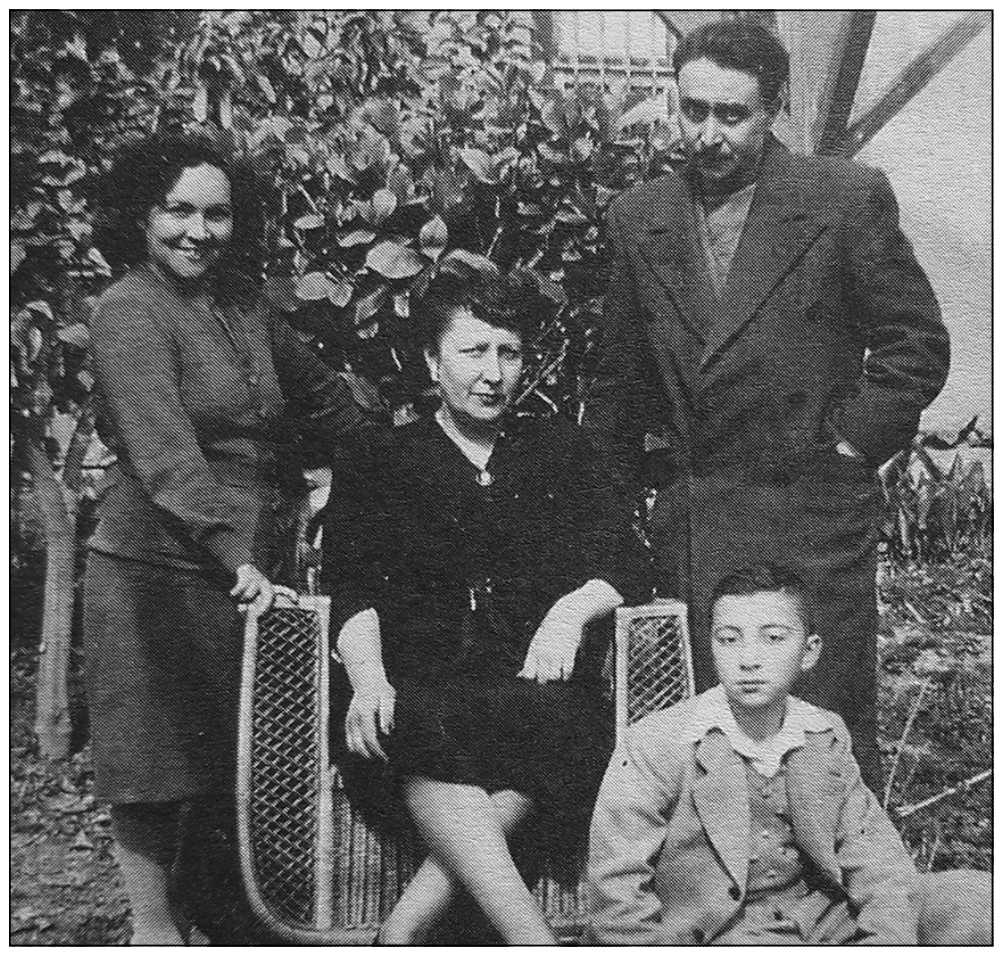

Figura 1. El poeta con su esposa Isolda Pradel (izquierda), su hermana Graciela Castro (sentada) y uno de sus sobrinos en 1945, año del diagnóstico de la enfermedad. Fuente: Libro "Obra reunida, poesía" Fundación Oscar Castro 2007. 
frecuentemente asociada a las bronquiectasias. Respecto a la tuberculosis recientemente diagnosticada, menciona una inicial buena evolución. En la misma línea, en carta del 27 de agosto, el poeta se percibe en mejores condiciones de salud y refiere aumento de peso:

"Presumo que Raúl te habrá informado en detalle de mi salud y por eso no te digo nada acerca de ella. Pero sabe que me siento sano. Es esa cosa psicológica del que no tiene toxinas en el organismo. Además, he ganado casi 5 kilos. Y esto me da firmeza $y$ seguridad".

Estas iniciales buenas noticias circulan en la correspondencia propia y la de sus amigos ${ }^{15}$, así en noviembre de 1945, Hernán Díaz Arrieta responde una carta al poeta indicándole:

"En fin, Ud. está mejor y va a sanar. Mi hermana, que vive conmigo, tiene a su marido cerca de San Fernando, conoce los baños del Flaco y dice que son prodigiosos. Vaya..."16.

Es probable que esta recomendación en alguna medida pudo influir en la decisión de acudir, en febrero de 1946, a este centro termal junto a su hermana Graciela Castro y sus hijos, desde allí, escribe a su esposa una carta fechada el día $10 \mathrm{del}$ citado mes:

"Isolda: "El Flaco" no me recibió tan bien como yo hubiera querido. Anoche dormí mal, semi-ahogado, y aún ahora no acabo de reponerme totalmente. Creo que este malestar se debe al esfuerzo de traer la maleta hasta Freire [...] Espero amanecer repuesto mañana"17.

En el contexto de la época resulta evidente que el poeta acudió buscando los beneficios atribuidos a las aguas termales y la altura moderada (1.750 metros sobre el nivel del mar). Un aspecto interesante, además de su carta, es que por primera vez se describe la disnea, que él atribuye a cargar una maleta. Su mala respuesta al medio sugiere una disminución de su capacidad física, que podría explicarse por algún grado de daño pulmonar. Un antecedente que refuerza esta idea es que el poeta viajó en 1945 a este mismo sitio, desde donde existen dos cartas a su esposa. En ellas, la única referencia a alguna molestia fue el episodio de "asma" descrito previamente ${ }^{14}$. Luego de un mes de este viaje, el 9 de marzo de 1946, le escribe a su amigo Drago, contándole la mala evolución de su cuadro:

"Ahora un poco de lo mío. Volví anteayer de mi último examen en el Servicio Médico de Santiago. Malas noticias. Van a pedir mi traslado a un sanatorio, porque el proceso sigue igual. Creo que me iré la semana entrante. Lo que ignoro es el sitio adonde me mandarán [...] algo se me derrumbó adentro cuando me notificaron la sentencia. Yo me creía sano y tenía el ánimo dispuesto a reincorporarme a mis tareas [...] Quisiera decirte mucho más, pero estoy decaído....".

Además de destacar la probable referencia a fatiga, en esta carta surge el antecedente que existe la idea de enviarlo a un tratamiento sanatorial formal. Desafortunadamente, durante el resto del año 1946 son escasos los documentos respecto a su estado de salud, sin embargo, es poco probable que asistiera a alguna entidad sanatorial, ante la falta de referencia en sus antecedentes biográficos en vista de la relevancia que habría tenido este hecho para su entorno. En todo caso, la revisión del "libro de firmas del personal" en el Liceo de Hombres, lo muestra tomando exámenes el día 6 de marzo, para luego ausentarse hasta el 13 de mayo de ese año. En este tiempo todo indica que guardó reposo en su casa. Luego de su reincorporación, permanece trabajando hasta diciembre, con algunas ausencias breves. Al final del año escolar, el artista tiene un problema en su trabajo, aparentemente por la realización de clases sin poseer el título necesario. Así, aprovechando que un colega ha sido nombrado rector en un colegio de Santiago, se traslada a esta ciudad a vivir a partir de marzo de 1947. Una vez allí, es unánime entre sus biógrafos las malas condiciones en que vivió, al respecto Drago señala:

"Instalado en una modesta pensión, mal alimentado, pésimamente atendido, respirando el aire viciado por los gases y las aglomeraciones humanas..."6.

González Labbé se refiere a las condiciones de vida del poeta como:

"El poeta mal alimentado dormía poco y mal en una pequeña pieza al fondo de un patio embaldosa- 
do. De un patio tieso y frío que se llenaba de gritos de jazz, dos noches por semana" 7 .

Finalmente, su esposa las describe como:

"El suyo es un pequeño cuarto en el que apenas puede darse vueltas, sin aire, casi sin luz natural, con una cama que más parece pocilga"18.

Los datos biográficos se pierden estos primeros meses de 1947, para reaparecer en una carta que escribe a su esposa en julio de ese año:

"Y yo estoy aquí, en mi cama, escribiéndote. Hace mucho frío y esta pieza está hoy tan helada como la otra de Santiago.[...]

Ivelda me preguntaba hace un momento allá abajo: “Qué le duele papito?”. Y yo le besé silenciosamente la cabeza. No me habría entendido: me duele la vida y soy un estúpido. Me duele la soledad y lo imposible"14.

La carta escrita a su mujer hace referencia a las precarias condiciones de su hospedaje en Santiago. Además, es explícito en describir sentimientos que pueden ser catalogados como de inutilidad y abandono que experimenta en los primeros meses alejado de su ciudad, de su familia y con la enfermedad pulmonar que avanza. A pesar que es imposible saber con exactitud cuánto afectó este período de grandes privaciones a su desenlace final, es muy probable que al menos este fue un factor agravante de su enfermedad. Así, en el mes de septiembre, su salud empeora, por esta razón acude al Servicio Médico nuevamente. Luego, escribe a su esposa:

\section{"Isolda:}

Fui ayer a la Preventiva y luego de mil trajines (no estaba el Dr. Rodríguez) pude averiguar lo siguiente: $1^{\circ}$ mi radiografía anterior salió mala: $2^{\circ}$ actualmente el Servicio Médico no tiene placas y no saben cuándo tendrán; $3^{\circ}$ una de las secretarias dijo que me habia despachado una citación a principios de este mes a Andes 4023. Nadie en el Liceo sabe de tal citación.

Hoy entre 11:30 y 12 tendré que ver al Dr. Rodríguez para preguntarle que hacemos. La Eliana Contesse, a quien llamé por teléfono, me ha dicho que averiguará en El Salvador si pueden sacarme una radiografía barata. Hoy en la tarde sabré la respuesta. También le preguntaréal Dr. si admitirán esto en la Preventiva.

Amanecí de nuevo con un poco de fiebre, pero entiendo que pasará más tarde.

Te mantendré al corriente de lo que vaya sucediendo.

Oscar"19.

Luego de ser reevaluado por el Servicio Médico fue declarado "irrecuperable", indicándole, además, que en adelante debía valerse por sí solo ${ }^{7}$. De esta forma, así como el poeta, inicialmente, se benefició de la Ley de Medicina Preventiva, también fue afectado por la exclusión que este instrumento legal hacía de los pacientes con estados avanzados de la enfermedad. Así, producto de la realización de gestiones de amigos y parientes, ingresa el 12 de septiembre de 1947 al Hospital del Salvador permaneciendo en la sala Cousiño, pieza $\mathrm{A}^{20}$. En este lugar estuvo bajo el cuidado de la máxima autoridad nacional en la enfermedad, el Dr. Héctor Orrego Puelma (1897-1995)21, quien decidió administrarle la moderna estreptomicina, descubierta en $1943^{22,23}$ por el Dr. Selman Waksman (1888-1973) y el Dr. Albert Schatz (1922-1995). Al momento, la mencionada droga era difícil de conseguir, tanto por su baja provisión como por su alto costo. Respecto a su evolución, no existen muchos antecedentes en ausencia de la ficha clínica, sin embargo, existen relatos de episodios de hemoptisis ${ }^{18}$, de una gran baja de peso, hasta alcanzar 42 kilogramos y que solo alcanzó a recibir algunos gramos de la droga ${ }^{24}$. De esos días, existe un testimonio gráfico (Figura 2) publicado por la revista Ercilla el 21 de octubre, que lo muestra en cama, enflaquecido, en compañía de su esposa. Aquellos últimos días, además, son descritos en una carta de González Labbé a Drago:

\section{"Querido amigo:}

Nuestro pobre Oscar está sencillamente grave: una T.B.C evolutiva de gran extensión lo tiene postrado y en franco peligro de abandonarnos. Esa es la cruda verdad. Lo veo continuamente en Santiago [...] Siempre la fiebre alta en las tardes, la tos, la inapetencia, la falta de sueño"”.

Esta carta completa la descripción de los síntomas extraídos de sus antecedentes biográficos: fiebre, tos, baja de peso, palidez, hemoptisis, disnea y fatiga. A lo anterior debemos sumar el 


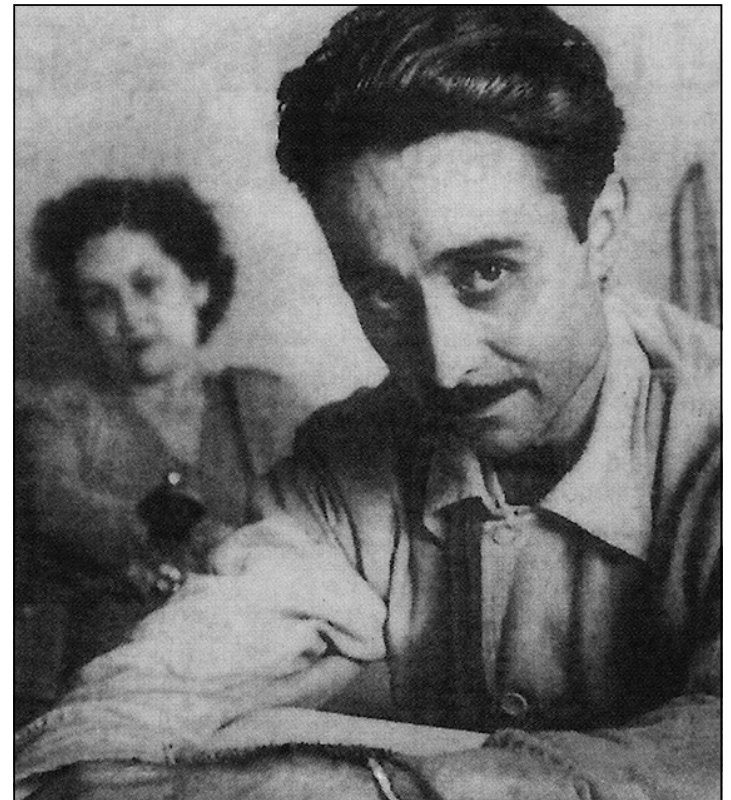

Figura 2. Oscar Castro durante su hospitalización en el Hospital del Salvador. De fondo se observa su esposa Isolda Pradel. Fuente: revista Ercilla.

mencionado antecedente de la bronquiectasia. Desafortunadamente, no existe registro de los exámenes de laboratorio y radiológicos hechos tanto en el Servicio Médico que lo controlaba como en su hospitalización, a pesar de esto, no existe duda de su diagnóstico.

En otro aspecto, al inicio de su hospitalización se lo describe con un buen estado anímico ante la posibilidad de una respuesta favorable al fármaco. Incluso, sus biógrafos mencionan planes de una internación posterior en una entidad sanatorial para recuperarse a cabalidad ${ }^{7}$. Con los días, este buen ánimo inicial va decayendo, a pesar de lo que siempre se mantiene escribiendo. Así, los días previos antes de su partida ${ }^{7,18}$ tiene la claridad e inspiración para escribir uno de sus últimos poemas, donde aparecen ideas de inutilidad, desesperanza y la muerte que avizora:

\section{Al fondo de un perfume tú vivías}

Al fondo de un perfume tú vivías. La noche abría sus azules puertas para que yo volara en tu recuerdo con el delirio de una abeja ciega.
Al fondo de un perfume tú vivías.

Yo cerraba los ojos para verte, y de mi alma surgías, temblorosa como la gota de agua entre las redes.

¡Cómo te alcé sobre mi vida inútil... En mis cumbres de amor, amanecías irisada de luz, en una lágrima. Al fondo de un perfume tú vivías.

Alta luna, celeste compañera, en mi valle de amor, agua y caricia, cuando mi corazón pliegue sus alas y se llenen mis ojos de ceniza, yo he de volverme flor para decirte: "Al fondo de un perfume tú vivías".

Oscar Castro fallece en la madrugada del primero de noviembre de 1947, dejando tras él un importante material literario inédito. Lamentablemente quedó atrapado en el momento que se inauguraba la era del tratamiento antibiótico que, en conjunto con la mejora de las condiciones sanitarias, finalmente terminarían con la epidemia de tuberculosis, dejando atrás la época sanatorial. Los potenciales beneficios de la estreptomicina llegaron tarde para él, probablemente producto de lo avanzado de su enfermedad. Así, se perdió tempranamente una promisoria figura de las letras nacionales, tal vez el último escritor relevante que falleció por esta causa en nuestro país.

Agradecimientos: Francisco Mora, encargado de colecciones, Museo Regional de Rancagua. Pedro Rojas, encargado de archivo, Liceo Oscar Castro Zúñiga de Rancagua, quien facilitó los libros de firmas y de clases de la época. Claudia Tapia, sección archivo del escritor, Biblioteca Nacional de Chile. Jorge Valenzuela Castro $(\dagger)$, sobrino del poeta, testigo directo de su enfermedad, quien aportó con su testimonio.

\section{Referencias}

1. Cabrera J. Comarca del Poeta Oscar Castro, su ciudad y su tiempo. Santiago: RIL editores; 2011.

2. Honorable Comisión Central del Censo. Memoria presentada al Supremo Gobierno por la Comisión Central del Censo. Santiago de Chile: s.n. 1907. http://historico. 
ine.cl/canales/usuarios/cedoc_online/censos/pdf/censo_1907.pdf

3. McCaa R. Chile XI censo de población (1940) Recopilación de cifras publicadas por la dirección de estadísticas y censos. Centro Latinoamericano de Demografía.

4. Castro O. Carta a Baltazar Castro, marzo de 1940 http:// www.bibliotecanacionaldigital.cl/bnd/623/w3-article-308668.html.

5. Agoni L. Oscar Castro aproximación en el recuerdo. Rancagua, Impresos Alerce; 1984.

6. Drago G. Oscar Castro Hombre y Poeta Epistolario. Santiago, Chile; Editorial Orbe: 1973.

7. González Labbé R. Luz En Su Tierra. Santiago, Chile; Editorial del Pacífico: 1973.

8. Pradel I. Raíces de la poesía y prosa de Oscar Castro. Rancagua, Chile; Ediciones Fundación Oscar Castro: 1999.

9. Castro O, Carta a Gonzalo Drago, 4 de junio 1945. http://www.bibliotecanacionaldigital.cl/bnd/623/w3-article-133546.html

10. Ley $\mathrm{N}^{\circ} 6.174$ establece Servicio de Medicina Preventiva. https://www.leychile.cl/Navegar?idNorma=25309

11. Duarte I, López M. Sanatorios para tuberculosos en Chile: primeros establecimientos (1886-1920). Anales Chilenos de Historia de la Medicina 2006; 16 (2): 21124.

12. Díaz Arrieta H. Carta a Oscar Castro el 10 de junio de 1945. http://www.bibliotecanacionaldigital.cl/bnd/623/ w3-article-133485.html

13. Díaz Arrieta H. Carta a Oscar Castro el 11 de julio de 1945 http://www.bibliotecanacionaldigital.cl/bnd/623/ w3-article-133490.html

14. Harris T, Zegers P. Epistolario íntimo de Oscar Castro. http://www.memoriachilena.cl/602/w3-article-9458. html

15. Guzmán N. Carta a Gonzalo Drago, 30 de agosto de 1945 http://www.bibliotecanacionaldigital.cl/bnd/623/ w3-article-308568.html

16. Díaz Arrieta H. Carta a Oscar Castro, 14 de noviembre de 1945. http://www.bibliotecanacionaldigital.cl/ bnd/623/w3-article-133491.html

17. Castro O. Carta a Isolda Pradel, 10 de febrero de 1946 http://www.bibliotecanacionaldigital.cl/bnd/623/w3-article-133471.html

18. Pradel I. Biografía de Oscar Castro. Rancagua, Chile; Ilustre Municipalidad de Rancagua: 1982.

19. Castro O. Carta a Isolda Pradel, septiembre de 1947. http://www.bibliotecanacionaldigital.cl/bnd/623/w3-article-133466.html.

20. Oscar Castro esta grave en el Salvador: confía en su cura: seis años demoró su nueva obra. Revista "Ercilla" (Santiago). 21 de octubre de 1947; 15.

21. Orrego H. Consideraciones sobre la tuberculosis en América del Sur. Aparato Respiratorio y Tuberculosis 1947; 3: 25-9.

22. Kingston K. Streptomycin, Schatz vs Waksman, and the balance of credit for discovery. Journal of the History of Medicine and Allied Sciences 2004; 59 (3): 441-62.

23. Schatz A, Bugie E, Waksman SA. Streptomycin, a substance exhibiting a antibiotic activity against gram-positive and gram-negative bacteria. Proc Soc Exp Biol Med 1944; 55 (1): 66-9.

24. ¡El poeta ha muerto! Oscar Castro Zúñiga falleció ayer. Diario "El Rancagüino" (Rancagua). 3 de noviembre $1947 ; 2$. 